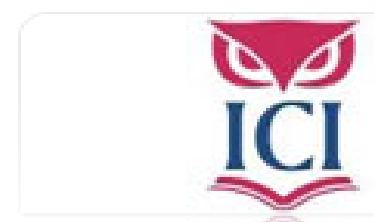

IUS. Revista del Instituto de Ciencias Jurídicas de Puebla A.C.

ISSN: $1870-2147$

revista.ius@hotmail.com

Instituto de Ciencias Jurídicas de Puebla A. C.

México

Barona Vilar, Silvia

JUSTICIA PENAL CONSENSUADA Y JUSTICIA PENAL RESTAURATIVA, ¿ALTERNATIVA O COMPLEMENTO DEL PROCESO PENAL? LA MEDIACIÓN PENAL, INSTRUMENTO ESENCIAL DEL NUEVO MODELO

IUS. Revista del Instituto de Ciencias Jurídicas de Puebla A.C., núm. 24, 2009, pp. 76-113 Instituto de Ciencias Jurídicas de Puebla A. C.

Puebla, México 


\section{JUSTICIA PENAL CONSENSUADA Y JUSTICIA PENAL RESTAURATIVA, ¿ALTERNATIVA O COMPLEMENTO DEL PROCESO PENAL? LA MEDIACION PENAL, INSTRUMENTO ESENCIAL DEL NUEVO MODELO CONSENTED CRIMINAL JUSTICE AND RESTORATIVE CRIMINAL JUSTICE; IS CRIMINAL JUSTICE AN ALTERNATIVE OR A COMPLEMENT? CRIMINAL MEDIATION, AN ESSENTIAL INSTRUMENT OF THE NEW MODEL}

\section{Silvia Barona Vilar*}

\section{RESUMEN}

En el nuevo panorama del enjuiciamiento penal ha resurgido la búsqueda de medios reparadores y restauradores, que sin entrar en conflicto frontal con la función restauradora del derecho penal, permite la introducción de medios alternativos al tradicional modelo del proceso penal que prevaleció y se fortificó durante todo el siglo xx. Se estudia la mediación penal como una de las vías alternativas en la solución del conflicto penal y su acomodo a las formulaciones constitucionales que han marcado las líneas del proceso penal tradicional, el papel de la víctima y de las personas que asumen la función de mediadores.

PALABRAS CLAVE: Proceso penal, enjuiciamiento criminal, mediación penal, principio de legalidad, principio de oportunidad

\section{ABSTRACT}

In the new criminal prosecution scene has revived the search for ways to repair and restore, without going into a confrontation conflict with the repairer function of the Criminal Law system, it allows the introduction of alternatives to the traditional Criminal Justice model that has prevail and was strengthen during the entire xx Century. Criminal Mediation is studied as an alternative means in the resolution of a criminal conflict and it's positioning in the constitutional formulas that have marked the traditional Criminal Procedure lines, and the role of the victim and of those who assume the function as mediators.

KEY WORDS: Criminal procedure, criminal prosecution, criminal mediation, principle of legality, principle of opportunity

* Catedrática de derecho procesal de la Universitat de Valencia y presidenta de la Corte de Arbitraje y Mediación de la Cámara de Comercio de Valencia. Recibido 3.08.2009. Aprobado: 2.10.2009. 


\section{SUMARIO}

1. Punto de partida: el derecho penal y el proceso penal, fundamento y función, ¿hacia dónde se dirigen?

2. La mediación penal, notas que la caracterizan e incidencia en la misma de las instancias supranacionales

A) Notas que caracterizan la mediación penal

в) Actividad desarrollada a favor de la víctima y de la mediación penal desde las instancias supranacionales

3. Coordenadas para la incorporación de la mediación penal al ordenamiento jurídico español. Fundamento en el principio de oportunidad y las funciones restaurativa y rehabilitadora presentes en el mismo

4. Tipo de mediación penal

A) Mediación penal atendiendo al tipo de negociación

B) Mediación penal en atención al momento procesal en que se desarrolla

5. Experiencias de mediación en España
A) Mediación penal en menores

B) Experiencias piloto

6. Experiencias en otros ordenamientos jurídicos

A) Gran Bretaña y Gales

B) República Federal de Alemania

7. Posibles infracciones penales susceptibles de mediación

8. Principios esenciales de la mediación

A) Principio de libertad o de voluntad de las partes

B) Principio de gratuidad

c) Principio de confidencialidad

D) ¿Principio de oficialidad o principio dispositivo?

E) Principio de dualidad de posiciones y de contradicción

F) Principio de flexibilidad

9. Procedimiento de mediación. Fases

10. El mediador y sus características

A) Requisitos para ser mediador

B) Facultades y obligaciones del mediador

\section{Punto de partida: el derecho penal y el proceso penal, fundamento y función, ¿hacia dónde se dirigen?}

El planteamiento que pueda efectuarse en torno a la posible aparición y fortalecimiento de la justicia penal consensuada y de la justicia penal restaurativa se halla intrínsecamente vinculado a ciertas cuestiones de índole plural, dogmá- 
ticas, procesales, constitucionales, políticas, orgánicas, económicas, formativas, profesionales, etc., cuya incidencia en el posicionamiento que se haga son esenciales a este respecto. Si bien, como punto de partida innegable puede avanzarse que el modelo penal que se afianzó a lo largo del siglo $x x$ ha entrado en crisis o quizás incluso la crisis es la consecuencia de una necesidad de evolución, de dinamismo, de búsqueda de porqués que en el modelo penal esencialmente retributivo no se hallan.

Así, el modelo penal del siglo $x \times 1^{1}$ se abre con cuestiones tales como la minimización versus la expansión del derecho penal, la eficacia de la pena y sus posibles alternativas, las nuevas tecnologías aplicables al modelo de tutela penal y a la propia delincuencia, la aparición de la delincuencia colectiva o masiva, el incremento de la violencia y de la lucha contra el terrorismo y su incidencia en los principios que conforman el derecho penal del Estado social y democrático de derecho, la aparición y consolidación de las instancias supranacionales e internacionales en materia penal, etc. Todas estas cuestiones han aparecido en el sistema penal y se han colado en los sistemas jurídicos, provocando una "crisis" de algunos de los postulados clásicos, cuestionándose inclusive el por qué y para qué el derecho penal y los medios para alcanzar la tutela efectiva, la necesidad de resucitar la figura de la víctima, su posible función en el sistema punitivo, e incluso la valoración de la conducta del delincuente y sus posibles repercusiones penales y procesales, entre otras.

Es innegable que el derecho penal cumple con fines de naturaleza preventiva y de control social. El componente del interés social planea en la configuración de cualesquiera modelo penal que se configure, amén de en su propia justificación. Ello no es óbice, sin embargo, a la consideración de que a través del derecho penal también se protegen los bienes jurídicos que se consideran indispensables en un modelo de convivencia y de paz que necesariamente incide tanto en los derechos sociales como en los derechos individuales. Precisamente por ese carácter incisivo y de intromisión que supone el derecho penal, ha sido una conquista de la civilización que fuera desapareciendo la autotutela como medio de resolver este conflicto, siendo la sociedad la determinadora de los parámetros de actuación penal, llegando a expropiar (confiscar, como apuntan algunos autores) los derechos de las víctimas. Se dice que los intereses individuales quedan protegidos a través de la tutela penal de los bienes jurídicos dignos de protección.

'Son distintas las obras que se han venido publicando en los últimos años en torno a estas cuestiones. Puede verse La ciencia del derecho penal ante el nuevo siglo, Libro Homenaje a Cerezo Mir, Madrid, Tecnos, 2003, o Derecho penal del siglo XXI (Dir.: Mir PuIG), Cuadrenos de Derecho Judicial, 2008, o La ciencia del derecho penal ante el nuevo milenio (Eser/Hassemer/Burkhard, trad. castellana dirigida por Muñoz Conde), Valencia, Tirant lo Blanch, 2004. 
Desde ese punto de vista es perfectamente comprensible que el monopolio en la aplicación del derecho penal se haya hecho recaer en el Estado, a través de los órganos jurisdiccionales y por medio del proceso. Es indudable que este sistema procesal penal ofrece objetividad y neutralidad, implicando en todo caso la intervención estatal en la asunción de la gestión propia del "conflicto" penal. Ahora bien, este modelo monopolizador estatal adolece de disfuncionalidades que crean sobre todo insatisfacciones personales e ineficacia en el propio sistema penal, e incluso existe en la doctrina quienes abogan por la consideración del sistema penal como ilegítimo, en cuanto para la solución de un conflicto, se limita a imponer un mal, una pena. ${ }^{2}$ Aún lejos de mostrarnos partidarios de esta posición, si consideramos que es de conciencia afirmar que toda posición crítica evita caer en la autocomplacencia y desde ese punto de vista también los abolicionistas y los minimalistas del derecho penal han aportado interesantes reflexiones que no son en absoluto desdeñables, obligando a replantear algunos de los postulados acríticamente ya mantenidos durante largas épocas.

Es por ello que en ese nuevo paisaje penal ha resurgido la idea de la fortalecer las funciones rehabilitadoras y reparadoras o restauradoras del derecho penal, sin mermar la posible concurrencia o coexistencia con la finalidad retributiva en ciertos casos. Y ello ha llevado igualmente a cuestionar si el proceso penal es el único medio instrumental a partir del cual o en el cual es posible cumplir con las funciones expuestas. Si bien en algunas constituciones se ha venido a consagrar como garantía esencial del modelo jurídico que la función punitiva sólo es posible ejercerse por los tribunales y a través del proceso, ello no es óbice a la posible colaboración de otros instrumentos o medios que permiten igualmente garantizar el efectivo cumplimiento de estas funciones descritas.

$\mathrm{Y}$ es por ello que se ha venido favoreciendo en muchos sistemas jurídicos la aplicación del principio de oportunidad o de oportunidad reglada, según los casos, permitiendo que se pueda hacer uso de la conformidad en el proceso, a través de acuerdos entre la fiscalía y el letrado del acusado, o se han consagrado determinados delitos de persecución privada en los que ha tenido una importante fuerza el perdón del ofendido, o incluso se han producido desviaciones del principio de legalidad en la persecución penal (en estricto sentido) como ha sucedido mediante la aceptación de la reparación como atenuación de la pena, o incluso se han permitido fórmulas como la suspensión de la pena o la sustitución de la pena privativa de libertad por otras consecuencias diversas, o el indulto, o en ejecución de pena la libertad condicional, entre otras. Poco a

${ }^{2}$ Larrauri, E, Bustos Ramirez, J., Victimología: presente y futuro. Hacia un sistema penal de alternativas, PPU, Barcelona, 1993, p. 108. 
poco la consolidación de estos mecanismos en el sistema penal ha generado no pocas modulaciones en un modelo estático retributivo y en el que el Estado aplica el principio de legalidad y el principio de necesidad como parámetros de actuación.

En ese contexto se habla también de la mediación penal, que, lejos de ser un instrumento desconocido, ha sido una pieza no escrita de todos los modelos, lo que significa que aun cuando el legislador no le vino dedicando durante siglos regulación alguna, precisamente porque en esencia responde a una clara y pura voluntad de las partes de acudir a la mediación, de querer llegar al acuerdo con ayuda del tercero y de, a la postre, cumplir con lo que acordado sin necesidad de coacciones, en estas últimas décadas la recuperación en unos casos, la puesta en escena de este procedimiento y su presentación en sociedad como un medio flexible, voluntario, desconflictivizador y favorecedor de todos los intereses en juego, ha llevado a que los legisladores lo quieran incorporar al modelo jurídico existente. Ni qué decir tiene que en otros ámbitos del derecho la mediación ya es pieza indiscutible, necesaria, como sucede en familia, en consumo, en comercio, etcétera.

Ahora bien, en el contexto en el que nos encontramos es importante insistir en que no es posible introducir sin más un procedimiento de mediación penal, regularlo en abstracto, sin replantearse el fundamento y la legitimidad de la misma. Su introducción comporta una metamorfosis, un elemento "extraño" al sistema penal clásico en ciertos ámbitos y exige por ello tener algunos elementos claros para su justificación y para su incorporación en este modelo de justicia penal. Hablar de mediación penal no es hablar sólo de un procedimiento -que lo es-; es hablar de sujetos partícipes de la "cosa" penal, a unos sujetos mediadores que deben saber cómo "dirigir", a unas normas que deben justificarla, tanto respecto al ámbito objetivo como al subjetivo, y a unas normas que deben otorgarle efectividad jurídica vinculante procesal, en su caso.

Todas estas cuestiones, y otras que afectan directa o colateralmente a la regulación de la posible mediación penal, no son fáciles de resolver, y ello aun cuando tímidamente algunos de los elementos que conviven con la mediación -como la participación de la víctima o como la actitud del imputado-acusado-condenado- pueden alterar algunas constantes del sistema. No se trata, evidentemente, de introducir una institución extraña, por cuanto existen manifestaciones -algunas de ellas mencionadas supra- en nuestro ordenamiento jurídico que la justifican y le pueden otorgar viabilidad. Ello no obstante, no basta esta fundamentación, sino que se requiere su adaptación en el modelo de justicia penal y ello implica replanteamiento de todo el modelo penal en este siglo xx. Cuestión que no osamos a plantear en un artículo ofreciendo la solución al mismo, empero sí queremos poner encima de la mesa algunas de esas dudas o 
cuestiones que indudablemente requieren una reflexión en profundidad, y no un parcheo, al que nos ha venido acostumbrando desgraciadamente el legislador.

Sí queremos ofrecer, pese a todo, en este trabajo algunas reflexiones en torno a esa manifestación de la justicia conciliadora, consensuadora y reparadora que es la mediación y a ella dedicaremos las páginas siguientes.

\section{La mediación penal, notas que la caracterizan e incidencia en la misma de las instancias supranacionales}

Existe una opinión generalizada en la consideración de que la mediación es un instrumento para gestionar el conflicto penal. Surge el primer interrogante de si es posible hablar de conflicto penal y si, a partir del mismo, deben concretarse quiénes son los sujetos que se hallan atrapados en ese conflicto penal. Y en este sentido, si bien desde un modelo eminentemente retributivo no hay verdadero conflicto penal porque el delito es una conducta antijurídica que pone en marcha al Estado y éste ejerce su ius puniendi, en un modelo no tan exclusivamente retributivo resurge la idea de conflicto penal y con ella de los sujetos que se hallan en conflicto, que son la víctima y el victimario.

En cualquier caso, y desde ese punto de partida, ora por las influencias externas ora por las carencias afloradas del sistema penal español, parece que en los últimos tiempos ha irrumpido desde diversos ámbitos y foros la propuesta de la incorporación legal a nuestro país de la mediación, una propuesta que propugna el diálogo entre el responsable criminal y la persona agraviada por el delito, sometiéndose ambos de manera voluntaria a este medio para conseguir un acuerdo al conflicto de manera extrajurisdiccional. E insistimos que no es un fenómeno local sino global, que se encuentra en la mayor parte de las legislaciones occidentales.

Este procedimiento puede finalizar con la obtención, por parte de la víctima, de una reparación, aun cuando está entendida en sentido maximalista y no sólo concretada en su naturaleza económica, de manera que la reparación no sólo permite que el autor haga frente al pago de los daños materiales o morales que se hubieren podido causar, sino que puede consistir en lo que se ha venido denominando una reparación social, que podría consistir, en su caso, por ejemplo, en la realización de trabajos en beneficio ya de la misma víctima o inclusive de la comunidad, exponentes que tendrían justificación cuando el responsable penal fuera insolvente, por ejemplo. Ello sin desdeñar asimismo el efecto positivo que podría jugar como medio de contraprestación en mediación de la posible disculpa o explicación del responsable a la víctima, generando en ciertos casos satisfacción adecuada o pertinente para entender alcanzada la efectividad de la mediación. 


\section{A) Notas que caracterizan la mediación penal}

Llegado a este punto es posible naturalizar la mediación penal en atención a las notas o características que la hacen propia. Así, podemos apuntar:

1) En primer lugar, la mediación es un procedimiento extrajurisdiccional en virtud del cual víctima e infractor, voluntariamente, se reconocen capacidad para participar en la resolución de un conflicto penal, con intervención del mediador, reestableciendo la situación previa al delito y el respeto al ordenamiento jurídico, amén de dar satisfacción a la víctima y el reconocimiento de tal actividad por el victimario. Se trata de un medio de gestión del conflicto, instrumentalizado a través del diálogo y favoreciendo la reconstrucción de la paz social quebrada por el hecho delictivo, lo que permite la minimización de la violencia estatal, devolviendo, en consecuencia, cierto protagonismo a la sociedad civil. Con todo, es indudable que se ha visto en esta opción una posibilidad de revertir de manera altamente positiva en la sociedad a través del incremento de confianza en la administración de justicia penal.

2) La incorporación de la mediación penal supone una inflexión en la concepción de la justicia penal, en cuanto:

$1^{\circ}$ ) El delito se convierte en conflicto, sustituyendo a la conducta antijurídica.

$2^{\circ}$ La víctima y el victimario son los principales actores.

$3^{\circ}$ ) Se da prioridad a la reparación del daño y a la prevención especial sobre la prevención general y la retribución.

$4^{\circ}$ ) La persecución de conductas amén del Estado permite la colaboración de los sujetos implicados en el hecho delictivo, lo que no afecta al principio de exclusividad de la jurisdicción penal ni afecta al monopolio estatal del ius puniendi, dado que serán, en suma, los tribunales los que van a controlar los resultados de la mediación y los que, en su caso, atribuirán o no eficacia jurídica a lo acordado en la mediación. Sigue por ello tratándose de un medio controlado judicialmente. Es más, lejos de considerarse como un medio de autotutela - prohibida en nuestro ordenamiento jurídico- estamos ante una modalidad autocompositiva intraprocesal que, a la postre, exigirá de una decisión judicial, ya para poner fin al proceso de forma anticipada -sobreseimiento por razones de oportunidad reglada- 0 ya para poner fin al proceso a través de la sentencia. 
в) Actividad desarrollada a favor de la víctima y de la mediación penal desde las instancias supranacionales

En este contexto descrito mucho han tenido que ver las instancias supranacionales, desde las que se ha potenciado ora la protección a la víctima ora el fomento de la justicia restaurativa y, con ella, la mediación penal de la víctima y el victimario. Podemos citar, entre otras, al respecto:

$1^{\circ}$ ) La Recomendación No. (83)7, de 23 de junio, del Comité de Ministros del Consejo de Europa, que pide a los gobiernos de los estados miembros que fomenten que se facilite la indemnización a la víctima por parte del delincuente, convirtiéndose ésta en medida sustitutiva de la pena privativa de libertad.

$2^{\circ}$ ) La Recomendación No. R(85)11 del Comité de Ministros del Consejo de Europa sobre la posición de la víctima en el marco del derecho penal y del procedimiento penal, de 28 de junio de 1985 , que recomienda a los gobiernos de los estados miembros examinar las posibles ventajas de los procedimientos de conciliación y mediación.

$3^{\circ}$ ) La Recomendación No. R(87)21 del Comité de Ministros del Consejo de Europa sobre la asistencia a las víctimas y la prevención de la victimización, de 17 de septiembre de 1987, que recomienda a los estados miembros favorecer los experimentos, en el ámbito nacional o en el local, de mediación entre el infractor y la víctima, y evaluar los resultados, observando en particular hasta qué punto sirven a los intereses de la víctima.

4) Recomendación No. R(92)16 del Comité de Ministros del Consejo de Europa sobre las reglas europeas sobre las sanciones y medidas aplicadas en la comunidad, que considera que las sanciones y las medidas que se cumplen en la comunidad son modos importantes para combatir el delito y evitar los efectos negativos de la prisión.

50) Resolución 1999/26, de 28 de julio de 1999, del Consejo Económico y Social de Naciones Unidas sobre el desarrollo y la aplicación de medidas de mediación y justicia reparadora en el derecho penal, que insta a los estados miembros, a las organizaciones internacionales y demás entidades a intercambiar información y experiencia sobre la mediación y la justicia reparadora.

60) La Comunicación de la Comisión al Consejo, al Parlamento Europeo y al Comité Económico y Social sobre las víctimas de delitos en la Unión Europea: Normas y medidas, de 14 de julio de 1999, que 
afirma que la mediación entre el delincuente y la víctima podría ser una alternativa a un procedimiento criminal largo y desalentador, en interés de las víctimas, y posibilita la indemnización del daño o la recuperación de los bienes robados al margen de un procedimiento penal normal.

7º Recomendación No. R(99)19 del Comité de Ministros del Consejo de Europa relativa a la mediación en materia penal, que establece unos principios que deben tener en cuenta los estados miembros al desarrollar la mediación en materia penal.

$8^{\circ}$ ) El Consejo Europeo de Tampere, de los días 15 y 16 de octubre de 1999, declaró en el punto No. 30 de sus conclusiones, que los estados miembros deberían instaurar procedimientos extrajudiciales alternativos.

9) Resolución del Parlamento Europeo, de 15 de junio de 2000, sobre la Comunicación de la Comisión sobre las Víctimas de delitos en la Unión Europea, que declara la importancia del desarrollo de los derechos de las víctimas del delito.

10) La Decisión Marco 2001/220/JAl del Consejo, de 15 de marzo de 2001, relativa al estatuto de la víctima en el proceso penal, que dispone en su artículo 10, que los estados miembros "procurarán impulsar la mediación en las causas penales para las infracciones que a su juicio se presten a este tipo de medida" y "velarán porque pueda tomarse en consideración todo acuerdo entre víctima e inculpado que se haya alcanzado con ocasión de la mediación en las causas penales". Por su parte, el artículo 17 dispone que los estados miembros pondrán en vigor las disposiciones legales, reglamentarias y administrativas necesarias para dar cumplimiento a lo establecido en su artículo 10, antes del 22 de marzo de 2006.

11\%) Recomendación No. (2006)8, de 14 de junio de 2006, sobre asistencia a las víctimas de las infracciones criminales, en cuyo Anexo, que reemplaza a la Recomendación 21 , se ocupa detalladamente de las definiciones de víctima, victimización y victimización secundaria, de la asistencia, del papel de los servicios públicos, de los servicios de asistencia a las víctimas, del acceso efectivo a los recursos jurisdiccionales, de las indemnizaciones acordadas por el Estado, de los seguros públicos y privados, de la protección de la integridad física y psicológica de las víctimas, de la confidencialidad, de la selección y formación del personal de los servicios, de la mediación y de la coordinación y cooperación internacional. 


\section{Coordenadas para la incorporación de la mediación penal al ordenamiento jurídico español. Fundamento en el principio de oportunidad y las funciones restaurativa y rehabilitadora presentes en el mismo}

Asumiendo, como punto de partida, que la mediación penal no debe considerarse de manera aislada sino vinculada estrechamente al modelo procesal penal y al modelo penal existente, hay que incardinar la mediación en el ordenamiento jurídico existente. De este modo, y aun cuando la misma se define y naturalice de manera similar en los diversos sistemas, cuando del derecho español se trata, las opciones pueden quedar reducidas a dos: por un lado, cabría regular de manera independiente la regulación del procedimiento de mediación, objeto del mismo, sujetos, estatuto del mediador, etc. Esa opción sería perfectamente adecuada a la incorporación de la mediación como instrumento al que se ha venido refiriendo la Unión Europea y las instancias supranacionales; por otro, cabría adaptar lo ya existente ubicando la mediación en la regulación penal y procesal. En cualquier caso, nuestro punto de vista se encuentra en la fusión de ambas posibilidades, a saber, modificar ciertas disposiciones de las normas materiales y procesales penales y la aprobación de la ley de mediación penal en la que se regularian objeto, sujetos, procedimiento y estatuto del mediador.

Cualquiera que sea la solución, debe repararse que su viabilidad, conformación, etc., debe efectuarse desde la base de la relación que existe o puede existir de la misma con ciertas instituciones ya existentes. Y, en este sentido, nuestro ordenamiento jurídico ofrece algunas instituciones y manifestaciones de la oportunidad que permitirian integrar con ellas y en ellas el procedimiento de mediación. Cabe citar en este sentido:

1) En el marco de la suspensión de la condena a que se refiere el artículo 80 CP. Dado que la reparación puede considerarse como medio para hacer efectiva la responsabilidad civil exigida para su aplicación, quedaría complementada si se hubiere participado en un procedimiento de mediación, en cuanto participaría la voluntad del infractor de rehabilitarse, de querer mantener voluntad tanto de reparar como de evitar la reincidencia, o lo que es mejor, favorecer su rehabilitación a través de tratamientos de desintoxicación, de ayuda psicológica, etc. (art. $81.3 \mathrm{cP}$ ).

2) Puede asimismo vincularse a la sustitución de la pena de prisión a que se refiere el artículo $88 \mathrm{cP}$, dado que precisamente reparar o el sólo hecho de su intento es elemento indiscutible para obtener esta sustitución. La voluntad de intervenir en el procedimiento de mediación es un síntoma de esa voluntas de cumplir con la condición legalmente establecida. 
3) Puede ser de interés en los supuestos de tramitación de un indulto, a que se refiere el artículo $4.4 \mathrm{cP}$, por cuanto a través de la mediación podría favorecerse la voluntad de reinserción social del penado, otorgando de este modo motivo posible de concesión del indulto. Con ello se llegaría a suspender, en su caso, la ejecución de la pena en tanto en cuanto se está tramitando el citado indulto.

4) Permitiría favorecer el pase a régimen abierto del artículo 72.5 LogP así como la posible concesión de la libertad condicional, y ello por cuanto la posible satisfacción de la responsabilidad civil así como la posible reparación o voluntad de realizarla influye en todos ellos, amén de la concesión, por ejemplo, de permisos, licencias, y en el mismo informe evolutivo que se realiza en relación con el tratamiento del sujeto. La mediación en esta fase debe considerarse como una voluntad de colaborar, una manifestación de buena conducta que va a jugar como un dato esencial para conseguir la libertad condicional de manera anticipada, a que se refiere el artículo $91.2 \mathrm{cP}$. Se trata de aquellos supuestos en que se ha querido participar en programas de reparación del daño.

5) Finalmente puede incorporarse asimismo a la posible supresión del periodo de seguridad que deberá decidir el juez de vigilancia penitenciaria a que se refiere el artículo $36.2 \mathrm{cP}$, en aquellos supuestos de personas condenadas a penas superiores a los cinco años: la participación en un procedimiento de mediación precisamente para llevar a cabo la reparación del daño a la víctima podría valorarse favorablemente en cuanto al tratamiento reeducador, lo que permitiría un informe positivo judicial de exclusión del periodo de seguridad.

\section{Tipo de mediación penal}

Para determinar las diversas modalidades de mediación penal pueden conjugarse una pluralidad de criterios, si bien nos parece de interés referirnos a dos de ellos: en primer lugar, a la manera en que se lleva a cabo la misma; y en segundo lugar, el momento en el que se produce y su vinculación con el proceso.

\section{A) Mediación penal atendiendo al tipo de negociación}

Esta primera modalidad responde a la técnica o manera en que se lleva a efecto la mediación, lo que nos permite diferenciar entre mediación directa y mediación indirecta. $^{3}$

\footnotetext{
${ }^{3}$ Puede verse Pascual Rodriguez, E., "Fase de negociación en la mediación penal con adultos. El encuentro entre las dos partes: persona víctima y persona infractora. Técnicas de negociación. Mediación directa e indirecta", en La mediación civil y penal. Un año de experiencia, Estudios de Derecho Judicial, No. 136, CGPJ, Madrid, 2008, pp. 170-171.
} 


\section{Mediación directa}

Es la que se desarrolla con las dos partes hallándose las mismas simultáneamente en el mismo espacio físico. Evidentemente se entiende que es más eficaz a los efectos de alcanzar el acuerdo, sobre todo por cuanto implica una mayor potenciación del diálogo. Su desarrollo debe estar precedido, por un lado, de entrevistas personales que permitan preparar de la mejor manera posible el cara a cara, amén de haber dado su consentimiento ambas para su realización, máxime cuando este método puede ser más perjudicial que la situación previa a la comisión del hecho.

Las experiencias ponen de relieve que en primer lugar se comienza trabajando con la víctima, y en breve llega el victimario, y es precisamente a partir de este momento cuando debe intervenir de forma habilidosa el mediador.

\section{Mediación indirecta}

Se trata de aquella negociación que se lleva a cabo de manera sucesiva, no simultánea con el mediador y las partes, de modo que no se da el cara a cara entre ellas, no coincidiendo físicamente en el mismo espacio la víctima y el victimario. La técnica de mediación en estos casos es diversa porque las habilidades del mediador irán dirigidas a convertirse en vehículo de transmisión de información de una parte a otra. Por la naturaleza del hecho puede ser conveniente que no exista el cara a cara y que las técnicas mediadoras lleven a la entrega de cartas explicativas y a petición de perdón, en su caso.

\section{B) Mediación penal en atención al momento procesal en que se desarrolla}

La segunda modalidad de mediación es aquella que puede considerarse atendiendo al momento en el que la misma se produce o puede producir y su vinculación con un proceso ya existente, ya fenecido o todavía no iniciado. Es por ello que hablaremos de mediación preprocesal, mediación intraprocesal y mediación postsententiam.

\section{Mediación penal preprocesal}

Supondría la consideración de la mediación como una verdadera alternativa y, por ende, excluyente del proceso penal cuando existiere acuerdo entre los sujetos intervinientes. Repárese que se trata de un modelo complejo y de difícil implementación en nuestro país, debido a que per se implica la exclusión de 
los tribunales y del monopolio procesal con las garantías que comporta en un modelo social y democrático de derecho.

Podría entenderse practicable en su caso en aquellos supuestos en que se asume la exclusión del principio de oficialidad a favor de la disponibilidad, lo que podría dar entrada a determinadas faltas, por ejemplo, y en general a aquellas conductas que podrían quedar despenalizadas, por el escaso nivel de reproche social.

El interrogante que esta modalidad de mediación genera es la de considerar si simplemente puede considerarse como una alternativa, excluyente del inicio de cualesquiera proceso, o si debe vincularse necesariamente a un proceso siquiera sea "ficticio" que debería homologar la mediación penal mediante una resolución judicial. Su viabilidad nos parece en nuestro sistema dudosa.

\section{Mediación intraprocesal}

Es la que se halla vinculada a la existencia de un proceso pendiente y, como tal, los resultados que se alcancen en mediación van a incidir en el proceso mismo, siendo las consecuencias jurídicas diversas según la fase procesal en la que se desarrolle y culmine la mediación.

Esta modalidad de mediación es la que ha venido funcionando en nuestro país, justificada sobre la base del artículo $21.5 \mathrm{cP}$, en los proyectos piloto que se han experimentado en nuestro país. Sin perjuicio de que es posible fundarla en este precepto, se requiere un soporte jurídico que dé mayor cobertura a determinadas cuestiones que se exigen para su desarrollo. Pese a todo, su estrecha vinculación con el proceso penal hace de esta modalidad de mediación complemento perfecto de la vía jurisdiccional. Repárese que el acuerdo que se alcanza, para ser eficaz y producir consecuencias jurídico-penales, debe quedar "validado" por el órgano jurisdiccional, en cuanto otorgará el efecto jurídico pretendido a estas modalidades de oportunidad reglada, a través de un auto de sobreseimiento, o, en caso de alcanzarse el acuerdo ya iniciado el juicio oral, a través de la sentencia de conformidad a la que a continuación me referiré, según el momento procesal en el que se trate, a saber, según nos hallemos en fase de instrucción -no se abriría juicio oral- o según ya se haya formulado acusación -en cuyo caso no queda otro remedio que dictar sentencia.

Es por ello que el mediador en estos casos viene a formular un acta de reparación o un informe en el supuesto de que no se alcance el acuerdo, que se presenta en el juzgado y se da traslado al fiscal.

Una solución adecuada sería que, en los casos en que se hubiere formulado ya acusación, existiese en el juzgado una vista oral a la que compareciesen los 
sujetos que intervinieron en mediación, a saber la víctima y el victimario, amén de sus abogados y el fiscal, pudiendo manifestar lo que consideren oportuno en relación con el acuerdo alcanzado e inclusive dándoles oportunidad de que puedan matizar, modificar algo de lo acordado, siendo de este modo mucho más respetuoso con los principios procesales esenciales. Y a partir de aquí cabría la posibilidad de que se dictase una sentencia de conformidad de viva voz.

\section{Mediación postsententiam}

Viene esencialmente circunscrita a los supuestos de mediación penitenciaria y en la que efectivamente los resultados pueden ser espectacularmente positivos para los condenados a pena de prisión y para el propio modelo penitenciario. Repárese a este respecto que en la to penitenciaria se regula un modelo disciplinario sancionador, con un catálogo de sanciones, que tipifica aquellas conductas que se consideran prohibidas y que son así consideradas por la comisión disciplinaria que las impone. Sin embargo, este modelo sancionador impositivo supone una posible intervención institucional para garantizar, en su caso, la protección de los bienes jurídicos de la integridad física y la vida de los internos y funcionarios, pero no trata de buscar el por qué de la conducta y la evitación futura de la misma sino que directamente declara e impone, sin evitar en este sentido esa idea represora y vengativa que genera. El régimen que se disciplina en esta legislación penitenciaria actualmente establecido no busca el diálogo y las soluciones duraderas, sino la solución a corto plazo y ello genera sensaciones de enfrentamiento, vencedores y vencidos. De ahí que se considere que la introducción de la mediación como instrumento del sistema sancionador penitenciario puede implicar una interesante alternativa al modelo actual, ofreciendo, por las técnicas empleadas, un método eficaz para la reducción de violencias dentro del ámbito penitenciario a través del aprendizaje de actitudes de respeto, escucha, diálogo y tolerancia. En suma, un cauce innovador en el sistema sancionador penitenciario.

Junto con la anterior posibilidad cabría cuestionarse hasta qué punto, dictada una sentencia de condena, no sería posible someterse a esta modalidad mediadora tras la misma. Para que pudiera barajarse esta posibilidad es indudable que necesitaríamos de una norma habilitante, que en estos momentos no tenemos en la LECrim. Podría, pese a todo, pensarse en los supuestos en que se puede llegar en ejecución de sentencia a una suspensión de la pena o a una sustitución de la pena privativa de libertad por otra, en cuyo caso cabría pensar en la bondad de un procedimiento de mediación con la víctima, a través del cual cumplir con las condiciones necesarias para su efectividad, tales como la reparación. Las reglas a seguir en cuanto a la información y a la confidencialidad que vendrían ofrecidas 
por el Servicio de Mediación serían las propias de cualesquiera mediación que se desarrolle y si se asumiera libremente habría que comunicarlo a los letrados, al juez y al fiscal, formando pieza separada de mediación. El resultado de la mediación puede ser elemento muy positivo a los efectos del cumplimiento de los requisitos y condiciones establecidos en esta fase de ejecución de sentencia y de la aplicación de los beneficios en la misma. Ese acuerdo en mediación deberá surtir efectos en la ejecución, lo que sólo podrá llevarse a cabo mediante una resolución judicial que deberá revestir la forma de auto en la que se aplique o no el citado acuerdo a efectos de ejecución.

\section{Experiencias de mediación en España}

España se ha venido mostrando algo más rezagada en las políticas de tutela de la víctima y de fomento de la mediación penal. Ello no obstante, se han ido introduciendo precisamente tímidas aportaciones para considerar en el proceso a las víctimas de los hechos delictivos, $y$, del mismo modo, la justicia restaurativa ha ganado adeptos entre los dogmáticos y los no dogmáticos, ofreciendo una fuente inagotable de posibilidades, que van desde su consideración en el marco de las consecuencias jurídico-penales, amén de instrumentos de naturaleza cautelar durante la pendencia del proceso, sin olvidar la tímida incorporación de la mediación penal en el ordenamiento jurídico español.

En este sentido, es especialmente importante destacar la aplicación de la misma y su buen resultado en el derecho penal de menores, desde la aprobación de la to 5/2000, de 12 de enero. De ahí que, como sucediera en los ordenamientos jurídicos de nuestro entorno, la mediación surgió en el seno de la delincuencia juvenil, si bien las experiencias pilotos que se han venido desarrollando en nuestro país en estos últimos años, el papel de colaborador ejercido por el cGPJ y la aparición de grupos de presión en política criminal que provienen de sectores de la judicatura, de la fiscalía, de la academia, etc., han venido forjando numerosos trabajos que han cuajado en una necesidad imparable de regulación en el sistema penal español.

Evidentemente es indudable que las exigencias de la Unión Europea desde la aprobación de la Decisión Marco del Consejo de la UE de 15 de marzo de 2001 (2001/220/JAI), relativa al estatuto de la víctima en el proceso penal, que conmina a los estados miembros precisamente a impulsar la mediación entre la víctima y el inculpado, es un acicate esencial en el convencimiento de la consolidación de este modelo reparatorio, menos agresivo para los sujetos y para la sociedad en su conjunto, más eficaz a largo plazo y más acorde con los principios de menor injerencia del derecho penal en su conjunto. 


\section{A) Mediación penal en menores}

La to 5/2000, de 12 de enero, que regula la Responsabilidad Penal de los Menores, recogía previsiones sobre la mediación, la reparación y la conciliación, diferenciándose, a tal efecto, entre la mediación como procedimiento dirigido a unos fines, y la reparación y la conciliación como objetivos a cumplir. Y quizás aquí podría diferenciarse, asimismo, entre la conciliación, que recae sobre la satisfacción psicológica que se otorga a la víctima por parte del infractor, y la reparación, que requiere, además, el cumplimiento del compromiso que se ha contraído para reparar el daño con la misma víctima. ${ }^{4}$

Repárese que las soluciones extrajudiciales que se han venido acogiendo en el derecho penal de menores encuentran su punto de referencia en las Reglas de Beijing y en las Recomendaciones del Comité de Ministros del Consejo de Europa. La regulación que a estos efectos interesa es la que se halla en los artículos 19 y 20 to 5/2000, en el artículo 27 de la misma y en el artículo 5 del Reglamento (en este precepto se regula el modo de llevar a efecto las soluciones extrajudiciales). Podemos apuntar como notas esenciales:

1) La mediación presupone la existencia de un expediente abierto.

2) Puede llevar, en consecuencia, al sobreseimiento y/o al archivo de las actuaciones, si bien continuará la tramitación procesal si el menor no cumple con la reparación o con la actividad educativa que se hubiere acordado.

3) Tanto la mediación como el seguimiento se lleva a cabo por un equipo técnico, compuesto por psicólogos, educadores y trabajadores sociales, si bien debe tenerse claro que se trata de un órgano que depende del fiscal de menores.

4) Las reformas que se han venido realizando de la citada ley han llevado a otorgar cada vez más un mayor papel a las víctimas en estos procesos, sin que ello afecte al sentido y fines del mismo.

5) Las fases procedimentales se desarrollan en el artículo 5 del Reglamento y esencialmente se refieren a:

- Iniciativa del fiscal. Si considera que es posible desistir de la continuación del expediente, se limita a solicitar del equipo técnico un informe acerca de la solución adecuada.

- Citación del menor por el equipo técnico, así como a sus representantes legales y letrado defensor, ofreciendo la solución extrajudicial. Si el menor o s su representante legal se negasen, el equipo lo comunicará al fiscal e iniciará la elaboración de un informe (si no, no se da este informe).

${ }^{4}$ Manzanares Samaniego, J.L., Mediación, reparación y conciliación en el derecho penal, Comares, Granada, 2007, p. 136. 
- Si se acepta, se contacta con la víctima para que manifieste su conformidad para intervenir en la mediación. Se realizará el encuentro para la concreción de los acuerdos pertinentes.

6) En relación con los efectos: podrá el acuerdo dejar sin efecto la medida que se hubiere adoptado, cuando juez, fiscal, equipo técnico... consideren que el acto y tiempo de duración de la medida ya cumplido expresan suficientemente el reproche que merecen los hechos cometidos por el menor. Inclusive es posible que la voluntad de conciliarse con la víctima se produzca precisamente durante la ejecución de la medida, en cuyo caso cabrá plantear una mediación en este momento procesal.

\section{B) Experiencias piloto}

Amén de la regulación legal en menores han sido y son ya diversas las experiencias que a lo largo de las dos últimas décadas han ido surgiendo en nuestro país y de las que sólo es posible afirmar que se han obtenido resultados prácticos de gran interés para la conformación de una regulación de la mediación en nuestro ordenamiento jurídico. Repárese que todas estas experiencias piloto se han producido sin norma habilitante, si bien entre sus conclusiones se halla la imprescindible recomendación al legislador de regular la institución de la mediación, estableciendo las normas objetivas y subjetivas, amén de procedimentales básicas, para su desarrollo.

Podemos citar las siguientes experiencias. En primer lugar se desarrolló en 1985 en Valencia la primera experiencia con adultos en España en mediación, gracias de la combinación entre el Juzgado de Instrucción No. 2 de Valencia y la Oficina de Ayuda a la Víctima del Delito, experiencia que trabajaba con unos 20 asuntos y que ofreció resultados positivos en la misma. Por su parte, desde 1989 se han desarrollado por el Departamento de Justicia de la Generalitat de Cataluña actividades de mediación con adultos. El Gobierno Vasco como propuesta de la Oficina de Ayuda a la Víctima también las impulsó en 1998 en los Juzgados de Vitoria. Destacan las actividades desarrolladas por la Asociación Apoyo de Madrid desde 2000, aun cuando ésta era una entidad cívica que nació en la década de los ochenta en el barrio de Moratalaz, y que ha estado realizando programas de mediación, apoyados por el decanato de Madrid y la Fiscalía del Tribunal Superior de Justicia de la Comunidad de Madrid. Igualmente, destacan las actividades realizadas como proyecto-piloto de mediación desde la Oficina de Atención a la Víctima del delito en la Rioja, en el año 2000, gracias a la colaboración del Gobierno de la Comunidad Autónoma y el Consejo General del Poder Judicial. En general pueden destacarse todas las experiencias piloto en las que 
ha colaborado el Servicio de Planificación y Análisis del cGPJ fundamentalmente desde 2005, junto a diversas asociaciones, como la Asociación de Mediación para la Pacificación de Conflictos de Madrid, de Navarra, Asociación ¿Hablamos? de Zaragoza, Arrats de San Sebastián, Amedi de Sevilla, Asociación Proderechos Humanos de Andalucía, Pastoral Penitenciaria de Vitoria, etcétera.

En algunos casos la actividad ha sido en gran medida favorecida por actividades voluntarias de determinados jueces, que han aceptado que sea desde su juzgado que pueda desarrollarse e implementarse estas actividades menos lesivas, menos incisivas y de naturaleza reparatoria. Así puede citarse, el Proyecto Piloto de Sevilla que se llevó a cabo gracias al convenio Colegio de Abogados de Sevilla con cGPJ, y en los juzgados de instrucción Nos. 13 y 18 de Sevilla; el que se desarrolló en el Juzgado de lo Penal No. 3 de Jaén con la Asociación para la Mediación Penal y Penitenciaria de Jaén; el que se lleva a cabo en el Juzgado de lo Penal No. 2 de Banalúa (Alicante), como proyecto del cGPJ; el del Juzgado de Instrucción No. 3 de Pamplona/Iruña, el del Juzgado de lo Penal No. 20 de Madrid, Juzgado de lo Penal No. 2 de San Sebastián, Juzgado No. 4 de Córdoba, Juzgado No. 1 de Bilbao, Juzgado No. 2 de Calatayud, y Juzgado No. 4 de Zaragoza, Juzgado de lo Penal 4 de Madrid en ejecutorias ${ }^{5}$ y se va a implementar en el Juzgado de Instrucción de Torrente próximamente.

Amén de los supuestos citados, resta por referenciar del mismo modo algunas experiencias piloto que se han llevado a cabo en el ámbito penitenciario, desde el año 2005. Se trata de experiencias de mediación entre los internos sometidos a procedimientos disciplinarios y supuestos de incompatibilidad; destacan en este sentido los llevados a cabo en los centros penitenciarios de Zaragoza, Madrid 111, Nanclares de Oca, Málaga y Pamplona. En ellos se ha trabajado con protocolos y los resultados hasta la fecha alcanzados permiten sin duda afirmar que pueden

\footnotetext{
${ }^{5}$ En este caso se trata en realidad de mediación en fase de ejecución y fue la consecuencia del plan piloto desplegado en el Juzgado de lo Penal No. 20 de Madrid desde el que se llevó la mediación en la fase de enjuiciamiento pero se designó el Juzgado de lo Penal No. 4 de Madrid para la ejecución de sentencias penales firmes dictadas por el resto de los juzgados de la capital. Los problemas se planteaban cuando se dictaba una sentencia condicionada a determinadas conductas que debía realizar el condenado en la fase de ejecución, siendo que las mismas no se cumplen, cambiando domicilio, ignorándose el paradero, etc. Ante esta situación Silva Fernández, Ma de la 0, "Cuestiones relevantes de derecho sustantivo y procesal de la incorporación de la mediación a la jurisdicción penal de adultos en la fase de ejecución", en Mediación civil y penal..., Op. cit., pp. 222-223. Esta autora realiza tres reflexiones: a) las normas de conducta que se señalen deben obedecer a criterios de realismo (atendiendo a las circunstancias personales del penado), previsibilidad de cumplimiento efectivo, y de fácil realización tanto en lugar como en tiempo: b) las reparaciones se desarrollen y tengan lugar en la mayor parte antes de la celebración del juicio oral; y c) control y seguimiento y acompañamiento por los mediadores del efectivo cumplimiento de las mismas hasta que finalice la ejecución de la pena. Esta opinión no la compartimos en absoluto, pues escapa claramente de las funciones del mediador. Se refiere a estas experiencias de la Comunidad de Madrid también Sánchez Álvarez, B., "Cuestiones relevantes de derecho sustantivo y procesal de la incorporación de la mediación a la jurisdicción penal de adultos en la fase de mediación. La mediación penitenciaria", en el libro colectivo Mediación civil y penal..., Op. cit., pp. 233-252.
} 
ser de gran utilidad como instrumentos para gestión de estos conflictos que tienen trascendencia disciplinaria. La Comunidad de Madrid ofrece interesantes resultados de estas experiencias que pueden destacarse. Así, sobre la base del protocolo de actuación elaborado en la Comunidad de Madrid en el año 2005 se desarrolló la mediación penal en la fase de ejecución.

\section{Experiencias en otros ordenamientos jurídicos}

Como se ha venido afirmando, aun cuando España está demostrando en estos últimos tiempos un interés palmario en la mediación, en su implementación en el modelo de justicia penal y en la proyección de actividades desde los juzgados con o sin el amparo protocolario del cGPJ, su actividad ha sido más tardía que la que han venido desplegándose en otros ordenamientos jurídicos. Así, son diversos los ordenamientos jurídicos que han venido acogiendo modelos de mediación inicialmente en el ámbito del derecho penal de menores, si bien en algunos sistemas se ha producido poco a poco una expansión, con diverso grado de intensidad, a los procesos penales de adultos. Destaca fundamentalmente en este progreso las experiencias vividas en el seno del mundo anglosajón, especialmente en Estados Unidos, que ha venido a consagrar un modelo de justicia inicialmente alternativa y en la actualidad integrada en el mismo poder judicial y en el que se ubica la mediación como método de solución extrajurisdiccional de los conflictos, a través de la denominada ADR (Alternative Dispute Resolution), extendiéndose paralelamente a Canadá y a Gran Bretaña y Gales. Los países de corte continental, aun cuando posteriormente, han venido acogiendo este modelo de mediación de forma escalonada; destaca la actividad desplegada en Francia, Holanda, Bélgica, Alemania, Austria, Noruega, Portugal, etc., a la que indudablemente pueden unirse países como el nuestro, en el que el modelo de mediación penal de menores funciona sin lugar a dudas, empero no ha culminado con la implantación legal del mismo o de un sistema similar en el ámbito de la justicia penal para adultos. Vamos a referimos a dos tipos de modelos, como manera de ilustrar lo que está sucediendo en otros sistemas jurídicos de nuestro entorno.

\section{A) Gran Bretaña y Gales}

Entre los primeros países que fueron consagrando la mediación entre víctima y victimario (victim-offender mediation, conocida con las siglas vom) se encuentran aquellos sistemas del common law, entre los que destaca en Europa el sistema británico y el sistema escocés, en los que se ha querido ubicar la me- 
diación como uno de los instrumentos de la justicia restaurativa. ${ }^{6}$ Son plurales los proyectos piloto que comenzaron en este sistema, comenzando en los años setenta en la ciudad de Exeter, aun cuando con menores; y a partir de aquí fueron apareciendo en diversas ciudades en la década de los ochenta, superando la treintena en 1985. Como sucediera en la mayor parte de los paises, se trató esencialmente de proyectos de vida efímera, resultado ora del voluntarismo ora de la falta de financiación que impidió su continuidad, si bien es indudable que su aportación a la consolidación de la justicia restaurativa fue indudable.

En las últimas décadas la política restaurativa ha recibido el apoyo del Ministerio del Interior británico, que aprobó en 2003 el documento Restorative Justice: the government's Strategy, ${ }^{7}$ lo que se ha venido uniendo a la aparición de una pluralidad de instituciones y organizaciones que han propugnado la justicia restaurativa, como la Victim Support, The National Association for the Care and Resettlement of Ofender (NACRO), The Jubilee Policy Group, The Howard League, The Restorative Justice Consortium, Mediation uk y The National Council for Social Concern. ${ }^{8}$ Con ello se ha producido una proliferación de organismos destinados a la de mediación.

Entre las notas más significativas de la mediación en estos sistemas jurídicos podemos señalar:

1) Es posible tanto la mediación previa al juicio (se trata de una mediación que se desarrolla por servicios de mediación que trabajan previamente a acudir a los tribunales y en los que la policía cumple una función esencial), como la mediación intraprocesales, así como la mediación tras la sentencia judicial.

2) Cabe respecto de cualesquiera delitos, no quedando circunscrito a delitos o faltas de menor entidad. El criterio es subjetivo y relativo, en cuanto se valoran, en su caso, los posibles beneficios de la mediación para las víctimas y los posibles delincuentes. ${ }^{9}$

3) Existe un interesante debate acerca de la modalidad de mediación, dado

\footnotetext{
${ }^{6}$ Repárese que no se trata la mediación de la única modalidad de justicia restaurativa sino que han aparecido otras como la restorative conferencing, muy similar a la mediación y que consiste en la reunión de cuantos se hayan visto afectados por un delito discutiendo y delimitando la manera de reparación del mismos; y los restorative cautioning, que se centran en la caución que el delincuente debe otorgar. Sobre estos temas puede verse el trabajo de Montesinos Garcia, A., "Modelo de mediación en Gran Bretaña y Gales", en la obra colectiva coordinada por Barona VILAR, S., Modelos de mediación penal en diversos ordenamientos jurídicos: Estados Unidos, Gran Bretaña y Gales, Taiwán y China, Francia, Alemania, Portugal, España y Brasil (2009), en prensa. A su vez puede verse Miers, D., y Semenchuk, M., "Victim-offender mediation in England and Wales", en Victim-offender mediation with youth offender in Europe (Ed. Mestizt, A. y GHETा, S.), Dordrecht, 2005, pp. 30-31.

${ }^{7}$ Vide http://www.sas.upenn.edu/jerrylee/jrc/restorativestrategy.pdf

${ }^{8}$ MarShall, T.F., Restorative justice, an overview, Informe del Ministerio de Interior británico, concretamente del Home Office Research Development and Statistics Directorate, 1999, disponible en: http://www.homeoffice.gov. uk/rds/pdfs/occ-resjus.pdf

${ }^{9}$ LieBmann, M. y Masters, G., "Victim-offender mediation in the uK", Op. cit., p. 337.
} 
que, por un lado, es posible hacer referencia a la mediación directa, que supone el encuentro cara a cara de la víctima y el ofensor, y por otro es posible hacer referencia a la mediación indirecta (shuttle mediation), que es aquella en que las sesiones se realizan sin confrontación cara a cara, a saber, de manera separada e individualmente con cada una de las partes. Quienes abogan por la primera modalidad sostienen que es más eficaz e incisiva, obteniendo mejores resultados que en la segunda, si bien los defensores de la segunda consideran que es mucho menos agresiva y causa menos lesión el enfrentamiento de ambos y favorece con ello a aquellas víctimas que no quieren enfrentarse a los autores.

4) Los principios esenciales que rigen el desarrollo de la mediación se asientan en la idea de la confidencialidad, aun cuando ésta no se extiende al resultado de la misma; ${ }^{10}$ asimismo, se rige por el principio de voluntariedad o libertad de aceptación por las partes de someterse a este procedimiento, lo que fundamenta la solución consensuada y no impositiva del mediador. Estos principios se conectan con las características propias del mediador, que llevan a considerar que debe ser neutral e imparcial para cumplir con su función de pacificador entre los sujetos intervinientes.

5) La mayoría de las mediaciones en este país siguen una estructura basada en cuatro fases esencialmente:

a) La primera de ellas, supone la preparación y aceptación del caso. Se le denomina Intake, y se produce como consecuencia de la remisión de la policía o de los mismos tribunales normalmente (o, en su caso, el fiscal, el equipo técnico...). Se admite esta mediación si el delincuente asume como punto de partida su culpabilidad.

b) La segunda fase es la de la preparación para la mediación (preparation for mediation), que consiste en la toma de contacto del mediador con cada una de las partes. Con esta fase se pretende favorecer un clima propicio para la mediación y que los sujetos que se acercan a ella no sientan que van a verse desfavorecidos por ella.

c) La tercera fase es la de la sesión propia de mediación, reuniéndose el mediador con las partes o con alguna de ellas por separado, según fuere la técnica empleada. Se trata de que las partes puedan plantear su versión de los hechos y las circunstancias en que éstos se produjeron. Su finalidad esencial es la de llegar al acuerdo reparatorio, al reconocimiento de la responsabilidad del sujeto y en su caso a la solicitud de perdón de la víctima.

Es interesante en estos sistemas observar cómo los sujetos que acuden a la mediación pueden no hacerlo solos, sino preferir ser acompañados por gente de su confianza, ya asesores jurídicos, familiares, personales, amigos, etcétera.

\footnotetext{
${ }^{10}$ Dignan, J., Atrinson, A., Atrinson, H., y otros, "Staging restorative justice encounters against a crimnal justice backdrop: A dramaturgical analysis", Criminology and Criminal Justice, 7, 2007, p. 18.
} 
d) Finalmente la última fase del procedimiento consistirá en el seguimiento del caso o también denominado follow-up. En ella se alcanza el acuerdo mediante la firma por escrito de las condiciones que se establecen para llevar a cabo la reparación, la modalidad de reparación, y los posibles esfuerzos que lleva a cabo cada parte para dar debido cumplimiento a lo acordado. Se lleva a cabo un seguimiento o evaluación de la mediación, controlando si se da debido cumplimiento a lo acordado.

Aun cuando quizás un poco menos desarrolladas, también la mediación en Escocia e lrlanda han ido alcanzado cotas cada vez mayores, si bien es indudable que el mayor número de resultados, actividades, proyectos e intereses se han mostrado en la mediación penal juvenil, desde 1968 en Escocia bajo la Social Work Act, para posteriormente -eso sí- ir poco a poco extrapolando las posibilidades de mediación a los adultos y esencialmente ubicada en el marco de la aplicación de las medidas de "diversión" o desvio del enjuiciamiento, al mismo tiempo que para otorgar un servicio de apoyo a las víctimas. Se implantaron en sus orígenes un proyecto piloto en Edimburgo en 1987 y en Glasgow en 1988, ambos operados por SACRO (Scottish Association for the Care and Resettlement of Offenders). Se trataba de supuestos en los que se había producido un aplazamiento del juicio. También aquí tuvieron vida limitada, pero fueron seguidos de otros proyectos, y en tal sentido se debe destacar los 18 proyectos financiados en 1997 por el Scottish Office, que propugnaban la mediación desde las fiscalías, referidas a delincuentes adultos, y que versaban esencialmente sobre hechos de menor gravedad.

Finalmente, en Irlanda también fueron apareciendo algunos proyectos en menores y en adultos desde 1985 pero no es posible afirmar que se trata de un mecanismo de justicia restaurativa ampliamente consolidado en el sistema penal. Ha sido recientemente, a partir de 2004 cuando se han realizado determinados proyectos de mediación en Dublín, que se han centrado en el ámbito de la delincuencia de adultos, lo que no es óbice a que la misma en menores funcione de forma fluida desde el 2001. Pese a no existir norma que dé cobertura jurídica y desarrolle la mediación como instrumento de justicia en menores y en adultos, sin embargo en la práctica judicial se ha venido ejerciendo por los tribunales un alto poder discrecional que permite ora suspender el juicio ora aplazarlo en aras de aplicar ya la mediación o ya cualesquiera otro modelo de justicia restaurativa que sea pertinente. ${ }^{11}$ Con el paso de los años se han ido consolidando estas modalidades de justicia restaurativa, si bien aún falta la consolidación de los mismos.

"KIERAN O'DWYer, "Victim-Ofender mediation with juvenile offenders in Ireland", Victim- offender mediation with youth offender in Europe, (Ed. MEstizT, A. y GHEпI, S.), Dordrecht, 2005, p. 47. 
Mientras que la mediación en la mayoría de los países se asocia a la delincuencia juvenil, en el Reino Unido perviven en la actualidad numerosos servicios de mediación tanto para adultos como para menores y ello aun cuando las normas que existen son referidas a menores. Si bien inicialmente arrancó como un arma de la "diversión" para evitar los tribunales, poco a poco se ha venido consolidando como un procedimiento que favorece a los sujetos, a las víctimas y a los delincuentes, en cualesquiera que fuere la etapa procesal.

\section{B) República Federal de Alemania}

Pese a las discusiones acerca de la bondad de la mediación penal en Alemania y su posible confrontación con el principio de legalidad, surgieron poco a poco diversos proyectos de conciliación autor-víctima (Täter-Opfer-Ausgleich) a mediados de los ochenta, ${ }^{12}$ aun cuando inicialmente en menores, generándose un interesante debate doctrinal que propugnó numerosas cuestiones en torno a la consideración de la reparación entre las funciones del derecho penal llegando a declararse, como hizo Roxin, que se trataba de la tercera vía o dritte Spur entre la pena y la medida de seguridad, ${ }^{13} \mathrm{y}$ ello pese a los detractores doctrinales, que también los hubo. ${ }^{14}$ Estos debates científicos no han cesado y de ellos son muchos los resultados alcanzados, como sucedió por ejemplo con la aparición de un movimiento con raíces igualmente en el mundo anglosajón preocupado por la víctima y que dio lugar a la victimología.

De interés es citar igualmente la celebración en 1984 del Deutscher Juristentag en Hamburgo, donde surgió la necesidad de la mediación entre víctima-delincuente, y el proyecto alternativo sobre reparación penal en el año 1992 (Alternativ-Entwurf Wiedergutmachung $)^{15}$ que impulsó la reforma penal y procesal penal para instaurar manifestaciones de justicia restaurativa. Se otorga a la reparación una función de reacción social ante la comisión de los delitos, convirtiéndola en tercera vía dentro de las consecuencias jurídicas, centrada esencialmente en la protección a la víctima y en la restauración de la paz jurídica.

\footnotetext{
${ }^{12}$ Los primeros proyectos comenzaron a surgir en los primeros años de la década de los ochenta, en 1985, y fueron 5 inicialmente, el de Braunschweig-Niedersachen, el de Handschlag en la ciudad de Reutlingen; en 1986, los proyectos Die Waage de Colonia y Gerichtshilfe de Tübingen, y en 1987 el proyecto Ausgleich-München/Landshut.

${ }^{13}$ Roxin, Claus, en Schöch (Ed.), Wiedergutmachung, 1987, p. 52. Como apunta Roxin no es la reparación un fin de la pena, dado que lo único que puede serlo es la prevención, sino que es una prestación de carácter autónomo que puede servir para alcanzar los fines penales tradicionales y que si lo consigue, sustituye a la pena o puede ser considerada para su atenuación.

${ }^{14}$ HiRsCH, Hans Joachim, "Wiedergutmachung des Schadens im Rahmen des materiellen Strafrechts" zstw 102 (1990), pp. 541-542.

${ }^{15}$ Puede encontrarse la traducción del texto del proyecto, realizada por Beatriz de la Gándara Vallejo, en Proyecto alternativo sobre reparación penal" (Proyecto de un grupo de trabajo de profesores de derecho penal alemanes, austriacos y suizos), Konrad-Adenauer-Stiftung, Buenos Aires, 1998.
} 
En 1994 se introdujeron las primeras manifestaciones en el artículo 46a StGB, y posteriormente en 1998 el ministro de Justicia federal designó una comisión de expertos cuya tarea era revisar el sistema de sanciones penales y preparar un informe con sanciones de contenido diverso que supusieren una mejora adicional de las existentes. En su informe final, que se publicó en 2000, se referían a la necesidad de impulsar el Täter-Opfer-Ausgleich y a la potenciación de los elementos restaurativos. Las modificaciones legales que se produjeron en estos años iban directamente orientadas ora a la protección de la víctima (como sucedió con la reforma del art. $46 \mathrm{StgB}$ ) ora a la consecuencia de la lucha contra el crimen, fomentándose las funciones de prevención, general o especial (reforma de 1994 en relación con el art. 46a StGB).

Algunas notas que permiten caracterizar al modelo alemán, son:

1) Aun cuando cabe la mediación con y sin institución, se ha apostado por la institucionalizada, que se denomina тоA. Se ha abogado por la profesionalización de los mediadores, que en unos casos intervienen con dedicación exclusiva y en otros parcial.

2) En la década de los noventa se ofreció el marco legal adecuado para su regulación, tanto procesal como penal. Con este marco legal se ofrece la posibilidad del TOA en cualesquiera que sea la fase procesal en la que se pretenda. ${ }^{16} \mathrm{Se}$ diferencia en Alemania entre la legislación común o básica y las legislaciones de los estados federales. De la legislación común podemos destacar:

a) Desde el punto de vista procesal, el fiscal decide la conveniencia de remitir a mediación el asunto o mantener la acusación en el proceso. Ello no es óbice a que el tribunal pueda igualmente considerar conveniente la mediación siempre que no se haya procedido a formular aún la acusación, en la fase pretrial (art. 153a.1, 1 y 5 de la Stpo y art. 45.2 y 3 Código Penal de menores). En 1999 se introdujo una disposición en el ordenamiento jurídico alemán en virtud del cual debe en cualquier etapa de la fase de la investigación o del juicio ponerse en

\footnotetext{
${ }^{16}$ Para más detalles puede verse Löschnig-GspandL, M. y Kilchuing, M., "Victim/Offender mediation and victim compensation in Austria and Germany - Stocktaking and Perspectives for Future Research", European Journal of Crime, Criminal Law and Criminal Justice, 1997, 5, pp. 58-78; HarTMAnN, A., KILChLING, M., "The development of Victim/Offender mediation in the German Juvenile Justice System from the legal and criminological point of view", in Walgrave, L. (Ed.), Restorative Justice for Juveniles, Leuven University Press, Leuven, 1998, pp. 261-282; Bannenberg, B., "Victim-Offender mediation in Germany", en European Forum for Victim-Offender Mediation and Restorative Justice (Ed.), Victim-Offender Mediation in Europe - Making Restorative Justice Work, Leuven University Press, Leuven, 2000, pp. 251-279; KıLChLIng, M. y LösCHnIG-GsPand, M., "Legal and Practical Perspectives on Victim/Offender mediation in Austria and Germany", International Review of Victimology, 2000, 7, pp. 305-332; Bannenberg, B., Delattre, R., "Germany", in Miers, D. and Willemsens, J. (Eds.), Mapping Restorative Justice, European Forum for Victim-Offender Mediation and Restorative Justice, Leuven, 2004, 67-75. Colofón de todos ellos es KILCHLING, M., "Restorative Justice Developments in Germany", en Regulating Restorative Justice. A comparative study of legislative provisions in European Countries, Op. cit., en prensa.
} 
conocimiento de los querellantes y los sujetos que intervienen en el proceso de las posibilidades de remitir al sistema de TOA para conseguir las finalidades propias de la justicia restaurativa (en tal sentido, el art. 155a de la StPo). Se ha venido convirtiendo en la norma procesal básica que ofrece a los sujetos la posibilidad de remitir la causa penal a la mediación. La regulación en Alemania viene a consagrar la máxima de que la reparación permite eliminar el interés público en la persecución del hecho y en la ulterior previsible condena penal. Esa reparación puede asimismo obtenerse por decisión de las partes, que llegan a acuerdo mediante una mediación no oficial. Cuestión diversa es la referida a las consecuencias procesales, dado que será el fiscal o el juez quienes decidan, en su caso, si se debe archivar el proceso o continuar con el mismo. ${ }^{17}$

b) Por su parte, en el ámbito penal destaca el artículo 46.2 de la StgB, modificado por la ley de protección a las víctimas de 1986. Y posteriormente, en 1994, con motivo de la regulación alemana de lucha contra la delincuencia grave, la remuneración a la víctima podía servir como atenuante de la pena, si se cumpliese con determinadas condiciones legalmente establecidas (art. 46a StcB). Se distingue entre remuneración o reparación a las víctimas, reparación parcial o inclusive tentativa de reparación (reparación simbólica). Se acogen cualesquiera que sea como contenido de la sentencia; y de no cumplirse, cabría revocarla, dada su naturaleza condicional. Producido el efectivo cumplimiento pueden cancelarse los antecedentes penales del condenado.

Es posible, asimismo, que la reparación a la víctima sea contenido posible que favorezca, una vez condenado el sujeto, la libertad condicional. Se tratará en estos casos de los supuestos en que el TOA puede jugar inevitablemente un papel importante en el seno de la ejecución penal de la sentencia. A esta posibilidad se refieren los artículos 56 y 57 del Stgi.

Por su parte y en relación con la legislación complementaria, merece destacarse que en los 16 estados federales, que tienen capacidad exclusiva sobre organización y administración de la justicia, se han venido conformando reglas generales y principios que traten de consolidar la exigencia de uniformidad en su aplicación. Pese a todo, el tratamiento recibido a lo largo del país es realmente dispar. Excepto en Baviera, ${ }^{18}$ todos los estados federales introdujeron normas o pautas específicas sobre el TOA; en algunos de ellos versan sobre derecho penal juvenil, mientras que en otros se regulan con carácter general.

\footnotetext{
${ }^{17}$ BANNENBERG, Britta, Wiedergutmachung in der Strafrechtspraxis. Eine empirisch-kriminologische Untersuchung von Täter-Opfer-Ausgleichsprojekte in der Bundesrepublik Deutschland, Forum Verlag Godesberg, Bonn, 1993, pp. 23-24.

${ }^{18}$ Reuber, S. y Rössner, D., "Sammlung der Länderrichtlinien zum Täter-Opfer-Ausgleich mit einer vergleichenden Analyse", en DBH-Materialien No. 49, Servicebüro für Täter-Opfer-Ausgleich und Konfliktschlichtung, Köln, 2003.
} 
Han sido tres los grandes temas que han querido expresamente referenciarse: la necesidad de la voluntariedad en el sometimiento al modelo; los deberes específicos de cada uno de los sujetos que intervienen, haciendo referencia en algunos estados al papel de la policía o incluso de los padres en el mismo; y los delitos que pueden plantearse a través de la mediación.

3) En relación con el ámbito de aplicación (esto es, qué hechos pueden llevarse a TOA y cuáles serían las condiciones para que los mismos pudieran ser objeto de sometimiento), se asume que cualquier delito podría ser objeto de TOA, cualesquiera sean, siempre que lleven una pena mínima de un año de prisión. Ese principio general se matiza por decisión judicial, cuando considere conveniente la aplicación de la función preventiva frente a la restaurativa. Los motivos pueden verse en la mayoría de los estados, mediante listas positivas o negativas de los hechos que pueden llevarse a los TOA. Por poner ejemplos, algunos estados federales excluyen de la mediación los crímenes sexuales motivados y los casos de la violencia doméstica. En otros casos se hace referencia a que el empleo de la violencia en la comisión del hecho debería ser motivo de exclusión de la mediación, o incluso el riesgo de peligrosidad para la víctima. Uno de los grandes debates en torno a la determinación de los delitos que deben excluirse de la posible mediación son los de la violencia doméstica y más aún los de la violencia de género; la razón no es otra que para que se pueda efectivamente proceder a dar debido cumplimiento a los fines de la mediación es imprescindible que se respete el principio de igualdad y que los sujetos en la mediación actúen de manera libre y sin presiones psicológicas. En tal sentido existen numerosas situaciones en que la mujer violentada no va a decidir libremente sino "sometida" al sometedor, por lo que difícilmente puede alcanzarse un acuerdo libre. Este debate es universal y no sólo se lleva a cabo en Alemania sino también en nuestro país. ${ }^{19}$

Asimismo puede considerarse, por otra parte, que no se exige que sean delincuentes primarios, sino que, aun con antecedentes penales es posible remitir a mediación. ${ }^{20}$

\footnotetext{
${ }^{19}$ En cualquier caso, y en lo que a Alemania se refiere, puede verse de KILCHLING, M., "Restorative Justice Developments in Germany", en Regulating Restorative Justice. A comparative study of legislative provisions in European Countries, $O p$. cit., en prensa. Este autor explica cómo en Alemania existe consenso en asumir que no debe excluirse a priori, máxime cuando existen supuestos, fundamentalmente centrados en el tema de la violencia familiar o doméstica, en que las relaciones que existen entre los sujetos son afectivas, de sentimiento, y van a perdurar, por lo que frente a una sanción impositiva, la solución consensuada que se alcance en mediación favorece la recomposición de las relaciones existentes y las que inevitablemente van a continuar en el futuro. Sobre esta cuestión específica pueden verse también, BAnNenBERG, B., Rössner, D. "New developments in restorative justice to handle family violence", en WetteKAmp, E., Kerner, H.-J. (Eds.), Restorative Justice in context. International practice and directions, CuIlompton, Willan, 2003, pp. 51-79.

${ }^{20}$ Así, a título de ejemplo, en el estado de Baden-Württemberg, a mediados de los años 90 sólo el $40 \%$ de los delincuentes que se sometieron a mediación eran primarios. Puede verse, al respecto, KLLCHING, M., "Restorative Justice
} 
En relación con las víctimas existe permisibilidad sea persona física o jurídica, sea individual o colectiva, sea determinada o indeterminada.

Inclusive se viene empleando otro criterio que puede afectar a las consecuencias dañinas que haya sufrido, sean materiales o sean morales, que pueden favorecer o perturbar la viabilidad del acuerdo alcanzable entre las partes.

4) ¿Quién asume la iniciativa de ir a mediación? En la reforma de 1999 se introdujeron algunas interesantes modificaciones en materia procesal en relación con la misma organización y estructura de TOA. Básicamente, derivado del artículo 155a de la Stpo debe afirmarse que las partes y el juez deben considerar en cualquier momento del procedimiento y del proceso las posibilidades de someter el asunto a mediación y alcanzar un acuerdo. De este modo, cuando así se considere, se remitirá a las dependencias del TOA, a salvo de que la víctima se oponga (art. 153a.3 Stpo). Si no existe oposición, la decisión de remisión se realizará de oficio, en atención a las circunstancias concurrentes y al supuesto de hecho planteado, amén de las características propias del sujeto presunto autor del hecho. Se otorga con ello un gran margen de discrecionalidad a la decisión judicial. La duda se halla en la posibilidad de que lo fuere la policia; sin embargo, la policía alemana no tiene esta posibilidad al no existir norma habilitante. Si pueden serlo las partes.

5) Efecto producido. El acuerdo puede provocar sobreseimiento o convertirse en contenido de la sentencia, condicionada al cumplimiento de las medidas reparatorias.

Desde el punto de vista penal, estas actividades pueden provocar la reducción o la eliminación de la pena si el delincuente intenta reparar o restaurar a la víctima (art. 46a StGB). No se trata de una medida de "diversión" aplicada, dado que en este caso hay sentencia condenatoria, sino en una posible medida de reparación de las víctimas que responde a una manifestación de la justicia reparatoria. En el caso de la "diversión", aun no existiendo condena real en la práctica, se mantienen los antecedentes penales, cosa que en mediación no sucede. Se produce inevitablemente una alteración de la aplicación de la norma penal común, en cuanto se produce una modificación de la consecuencia jurídica que en principio debería llevar aparejada la comisión del hecho. El comportamiento de reparar se valora desde un grado de menor culpabilidad del autor. Esta decisión es recurrible.

Además de lo anterior, la posibilidad de la remuneración o la posible mediación que se impone en fase de ejecución, y como condición de la libertad condicional es bien vista en la doctrina. A pesar de ello no existen estadísticas

Developments in Germany", en Regulating Restorative Justice. A comparative study of legislative provisions in European Countries, Op. cit., en prensa. 
judiciales disponibles que permitan determinar el grado de eficacia de las mismas y las bondades que ellas producen. En todo caso en Alemania se considera de manera restrictiva la posibilidad de la justicia restauradora postsententiam, no regulándose con carácter general, como sucede en Austria, una norma que permita a posteriori una atenuación de la pena.

En el año 2006 se introdujo una reforma en el artículo 42.3 del Código Penal a través de la Ley de modernización del sistema de justicia de 22 de diciembre de 2006, por medio del cual se incorpora una cláusula que permite que los pagos por reparación a las víctimas, en aquellos supuestos en que los medios económicos del delincuente sean limitados, se consideren prioritariamente a la exigencia de cumplimiento de ejecución de las multas. Cuando se hace referencia en este precepto a los pagos por reparación se entiende que también se incluye en los mismos a aquellos que se derivan de la conclusión de un acuerdo adoptado en el seno de una mediación o confrontación víctima-victimario, pero sin que ello se haya querido considerar por la doctrina como una posible regulación restaurativa de la justicia en sentido estricto.

6) En cuanto a los centros de mediación: si bien inicialmente eran privados, fueron poco a poco creciendo los de naturaleza pública o semipública, como los que se refieren a los proyectos antes meritados. El personal que trabaja en los mismos puede hacerlo con dedicación parcial o exclusiva, no existiendo límites a este respecto. En la mayoría de ellos se funciona por financiación de los estados federales.

\section{Posibles infracciones penales susceptibles de mediación}

Son significativas las experiencias piloto que se han venido desarrollando en nuestro país, amén de las que se conocen en otros ordenamientos jurídicos. De todo ellos podemos extraer algunas conclusiones de interés.

1) Como punto de partida, no debería a priori excluirse ninguna infracción penal, sino que debería ser resuelto en cada caso concreto y atendidas las condiciones concurrentes, siempre que no se pueda producir un quebrantamiento principio de igualdad de las partes intervinientes. Lo razonable por ello es que no exista una enumeración cerrada de supuestos en que pueda acudirse a mediación.

2) Cabría, pese a la afirmación general, plantearse la posibilidad de restringir o limitar la mediación a los supuestos que no fueren especialmente graves. La gravedad podría jugar como elemento de exclusión, aun cuando no es así en algunos ordenamientos jurídicos y además hay quien defiende que si fuera así se privaría en ciertos casos de la posibilidad de que la víctima y el acusado pudieran beneficiarse de los efectos positivos de la mediación. 
Ello no niega la premisa inicial como punto de partida y ello por cuanto pudiera suceder que en determinados asuntos graves la víctima se halla en posición poco propicia al diálogo y, en consecuencia, no pueda darse debido cumplimiento al principio de igualdad, lo que enervaría la posible virtualidad de la mediación, careciendo de sentido "someter" a la misma a quien no va a obtener los efectos positivos de la misma.

3) A título de ejemplo, los delitos contra el patrimonio suelen, por la práctica conocida, ofrecer coordenadas muy apropiadas para alcanzar con éxito los resultados de la mediación y especialmente la reparación (hurto, robo con fuerza, robo con violencia o intimidación, robo y hurto de uso de vehículos, estafas, insolvencia punible, daños y receptación). Es por ello que se ha venido propugnando la consideración prioritaria del tratamiento este tipo de delitos con procedimientos de mediación.

Por su parte, $\mathrm{y}$ en lo que a faltas se refiere, existe una posición maximalista en la consideración de la mediación como instrumento a través del cual proceder a conocer de las mismas. Es por ello que se sostiene que pueden ser de aplicación en todas las faltas menos en las recogidas en el título 11 y ello por la naturaleza de estas faltas, en las que se hallan en juego los intereses generales, y del mismo modo parece conveniente excluir las faltas del título iv, que son las referidas al orden público. Entre ellos cabe citar los delitos de atentado o los cometidos por funcionarios públicos en el ejercicio de su cargo.

Además cabría pensar a priori como delitos susceptibles de mediación los delitos de lesiones, los delitos contra la libertad como amenazas o coacciones, los delitos contra el honor, como las injurias y calumnias y los delitos contra los derechos y deberes familiares tales como el impago de pensiones, y asimismo cabría pensar en los delitos contra la salud pública, en cuanto cabría hacer referencia a las denominadas reparaciones de naturaleza simbólica o a la comunidad.

4) Pese a las consideraciones anteriormente expuestas, existen, sin embargo, algunas modalidades delictivas que suscitan cuando menos dudas acerca de su viabilidad. Pasamos a considerar algunos de estos supuestos.

Uno de los supuestos que ha planteado dudas en la doctrina ha sido el de los delitos de violencia de género. ${ }^{21}$ El legislador quiso excluir en el artículo 44.5 de la 10 1/2004 la mediación en estos casos, aun cuando no está claro que se refiriese al ámbito civil solo o también la exclusión se extendiese al ámbito penal. Evidentemente es indudable que existen numerosos supuestos en los que la aplicación de la premisa primera expuesta daría como consecuencia la negativa a

\footnotetext{
${ }^{21}$ Un desarrollo interesante de esta materia puede verse en la obra de EsaUINAS VALVERDE, P., Mediación entre víctima y agresor en la violencia de género, Valencia, Tirant lo Blanch, 2008.
} 
considerar como viable la mediación en estos casos, y ello por cuanto los sujetos víctima y victimario se hallan en una posición de desigualdad, en la que la mujer se encuentra "sometida" a su victimario y ello impide el diálogo, el consenso y el acuerdo de ambos. Salvados estos supuestos, que son numerosos, pueden darse supuestos en que el perdón, la explicación de los hechos, el reconocimiento de la culpa, etc., pueden ser muy útiles para una posible relación que pudiera perdurar. Destaca, a este respecto, cómo en las experiencias que se conocen con mediación penal en adultos los conflictos que se suscitan en el ámbito de los conflictos familiares está resultando efectiva la mediación, muy probablemente porque en estos supuestos los sentimientos están muy presentes y la ayuda del psicólogo puede ser esencial para que las relaciones se modulen, puedan recomponerse 0 simplemente alterarse en cuanto a las perspectivas de futuro, de ahí que en los delitos de violencia familiar existan supuestos de mediación con éxito.

Otro de los supuestos es de mediación con personas reincidentes, en los que existe una cierta reticencia en incluirlos, lo que a priori puede implicar un uso excesivo de las etiquetas, máxime si se piensa que aun cuando alguien pudo ser reincidente, las circunstancias personales, sociales, etc., que le rodearon pueden ser claramente diversas en los momentos en que se produce el hecho y la mediación puede jugar de manera esencial en la recomposición de las relaciones entre víctima-victimario y servir de canalización para una verdadera rehabilitación del sujeto. Serán por ello los mediadores los que deben valorar, caso por caso, si la mediación es, o puede ser, útil a los efectos pretendidos o si sería un mero obstáculo a salvar sin efectos positivos para los sujetos.

Por su parte, también se ha cuestionado la viabilidad de la mediación en los delitos de peligro. Quizás en estos casos el obstáculo mayor que se argumenta es la inexistencia de víctima singularizada, como sucede, a título de ejemplo, en los delitos contra la salud pública. No existe unanimidad acerca de la necesidad o no de que la víctima sea concreta dado que hay quienes defienden la existencia en estos supuestos de una denominada "víctima simbólica", como podrían serlo en los asuntos de drogodependencias quienes se hallan sometidos a un proceso de desintoxicación de estas sustancias, en alguna asociación destinada a este efecto, aun cuando ello no es en todo caso tan sencillo. Obviamente, y aun cuando nada es imposible, cierto es que se trata de determinados hechos que complican, cuando menos, el desarrollo de la mediación y su efectividad, en su caso. ${ }^{22}$

Se plantean igualmente dudas acerca de la mediación en supuestos con una pluralidad de sujetos, en los que por ejemplo, siendo varios los acusados, no

${ }^{22}$ Interesantes son las conclusiones al curso sobre mediación civil y penal de Rios MARTin y OLAVARRiA IGLESIA, en la obra colectiva Mediación civil y penal, Op. cit., p. 265. 
todos quieren someterse al procedimiento de mediación. Repárese que el reconocer los hechos por alguno de ellos está afectando o puede afectar tanto a la presunción de inocencia de los demás como a su propio derecho de defensa. Estos son obstáculos que deben valorarse a la hora de admitir y considerar para unos hechos la mediación sólo parcialmente subjetiva. Probablemente en muchos casos la misma no se haga recomendable.

lgualmente se ha cuestionado la viabilidad de la mediación con víctimas menores de edad o incapaces, y se entiende que en estos supuestos la mediación podría desplegarse pero necesitaría la intervención de las personas que legalmente les representen, amén del Ministerio Fiscal. Ello dificulta en todo caso el dar debido cumplimiento a los objetivos de la mediación, por cuanto no es la persona en sí la que libremente está tomando parte para asumir las consecuencias que se deriven de la misma.

Se ha venido excluyendo, igualmente, un grupo de delitos, entre los que se hallan los delitos de atentados, de resistencia y aquellos que pudieren ser cometidos por funcionarios públicos, dado que el principio de igualdad no se daría en estos casos. Si bien, como sucede en los supuestos anteriormente expuestos será el mediador el que en cada caso concreto debiera decidir conveniente o no la mediación, y ello aun cuando parece que a priori no van a ser los casos más adecuados para alcanzar con plenitud los fines de la mediación.

\section{Principios esenciales de la mediación}

Llegado a este punto pueden determinarse cuáles son los principios que deben conformar el modelo de mediación penal, salvaguardando a los sujetos que intervienen en el mismo, de igual modo que se lleva a cabo en el proceso penal, y vinculándola a las garantías esenciales de todo ciudadano referidas esencialmente al derecho de defensa, el derecho a la libertad y a la presunción de inocencia.

De todo ello, en consecuencia, puede concluirse que las características esenciales del modelo de mediación que se propone son las siguientes: ${ }^{23}$

106

A) Principio de libertad o de voluntad de las partes

Acudir a mediación es un verdadero acto de libertad de la víctima y del infractor, lo que implica no coerción. De ahí que se venga exigiendo la información del significado de la mediación, las fases del procedimiento y las consecuencias que

\footnotetext{
${ }^{23}$ Muchos de estos principios han quedado reflejados en las conclusiones de Rios Martín y OlavarRia lglesia, en la obra colectiva Mediación civil y penal..., Op. cit., pp. 258-261.
} 
pueden derivarse de la misma. Es por ello que se viene exigiendo en los procedimientos de mediación la firma de un documento en el que consten la voluntad de sometimiento a este procedimiento por ambos y el conocimiento de lo que la mediación comporta. Esto no implica, pese a todo, que el imputado acepte ir a mediación porque está reconociendo los hechos en esa primera toma de contacto. Antes al contrario, acudir a mediación no puede significar en sí misma un reconocimiento de la culpabilidad o de la comisión de los hechos porque de lo contrario se estaría vulnerando el principio de presunción de inocencia.

\section{B) Principio de gratuidad}

Se ha venido entendiendo de manera muy acertada que el procedimiento de mediación debe ser gratuito. La razón de este principio se basa en la necesidad de considerar que estamos ante un procedimiento de naturaleza pública en el que los gastos deben asumirse por la administración de justicia, como componente del sistema que es.

\section{c) Principio de confidencialidad}

Este principio es la esencia de la mediación, de manera que no deben transmitirse al juez los diálogos, debates, afirmaciones o alegaciones que se hayan realizado por las partes, sino tan sólo conocerá del documento final, que es algo así como un acta en la que se suscriben los posibles acuerdos, o no, de las partes. Es por ello que tras la información correspondiente a las partes de lo que es la mediación, el mediador hará firmar un acta o documento de confidencialidad a las mismas, con el fin de evitar que se pueda atribuir cualquier valor incriminatorio a lo expuesto en mediación. Lo contrario supondría un claro atentado al principio de presunción de inocencia, y provocaría un gran recelo sobre todo por parte del infractor de participar en este procedimiento. Precisamente por ello, el mediador nunca podrá ser llamado al proceso ni como testigo ni como perito. Es por ello que, precisamente, para garantizar este principio, se dice que el mediador no puede ser llamado al proceso como testigo o como informante porque implicaría un atentado a este principio de presunción de inocencia.

\section{D) ¿Principio de oficialidad o principio dispositivo?}

Es posible asumir que tan sólo le corresponde al juez o al fiscal o incluso al equipo técnico ofrecer la posibilidad de la mediación a las partes, si bien no vemos dificultades en considerar que pueda ser decisión de las mismas el acu- 
dir a mediación. Quizás podría existir una situación intermedia en la que aun siendo propuesta por las partes, deba ser de oficio la decisión final de remitir o no al procedimiento de mediación. En general podría pensarse en que lo común debiera ser que una vez se han incoado diligencias, se le informe por el mismo juzgado en el que se le hayan abierto, de la posibilidad de realizar mediación, comunicándose e informando igualmente a la víctima, derivándoles, en su caso, a un Servicio de Mediación, quien tras informarles de lo que es la mediación y sus consecuencias, sería el que, en su caso, se comunicará con el abogado del imputado para darle la información pertinente.

\section{E) Principio de dualidad de posiciones y de contradicción}

Se hace necesario que el procedimiento de mediación se desarrolle entre dos sujetos que mantienen posiciones diversas y a los que se les debe dar oportunidad de ser oídos a lo largo del procedimiento. Las técnicas de la contradicción pueden ser diversas según el tipo de delito y las circunstancias concurrentes, de manera que es posible una contradicción simultánea, que consistiría en el diálogo simultáneo o confrontación cara a cara, o bien es posible el diálogo personal y separado; en ambos casos a las partes se les permite ser oídas y se les da las mismas posibilidades de intervención, ya fuere con confrontación simultánea o ya a través de entrevistas individuales. Todo ello no es óbice a la posible participación de terceras personas en el procedimiento colaborando con los sujetos directamente implicados.

\section{F) Principio de flexibilidad}

Esta característica es innata a un procedimiento de mediación, de modo que, sin perjuicio del posible establecimiento de determinados plazos -el más importante es el de la suspensión de los plazos a efectos de prescripción- como el de la suspensión del proceso penal para llevar a cabo la mediación o inclusive plazos de emisión de informes que pueden exigirse a los mediadores, parece mucho más coherente con el significado pretendido a la mediación, que exista flexibilidad en el desarrollo de los diálogos comunes, de las entrevistas individuales y en suma del propio procedimiento de mediación, así como del tiempo empleado para alcanzar los fines esenciales de reparación.

Este principio de flexibilidad debe afectar a las garantías esenciales que en la legislación procesal se otorgan a los sujetos del proceso, y especialmente al imputado, de manera que el respeto a los derechos esenciales de igualdad, contradicción, derecho de defensa o presunción de inocencia deben estar presentes también en la actividad desplegada en el seno de la mediación. 


\section{Procedimiento de mediación. Fases}

Siguiendo con algunas de las experiencias que los proyectos-piloto han ofrecido resulta interesante configurar unas mínimas fases para el desarrollo del procedimiento de la mediación, si bien debe tenerse en cuenta, como punto de partida, que no debe ser un procedimiento rígido, dado que la pluralidad de situaciones y de coordenadas que pueden concurrir, ofrecen un variado abanico de exigencias que no deben quedar constreñidas mediante un procedimiento rígido, sino, más bien, desde unas fases generales, que serán más o menos largas y complejas en atención a los supuestos que se vayan suscitando. Establecer un procedimiento rígido de mediación comportaría una negación de la eficiencia y buena virtualidad del sistema y ello por cuanto la flexibilidad del modelo es una de las grandes bondades del mismo y siempre habrá que pensar que algunos cambios en el procedimiento se darán en función de cuál sea la técnica de mediación empleada y el momento en el que la mediación se desarrolla, si antes, durante o después del proceso.

Los sujetos que intervienen en la mediación, como mediadores, deben por ello estar capacitados y formados para saber cómo desarrollar cada una de estas fases y en qué supuestos alguna de ellas puede significar la no continuidad o, por el contrario, la necesidad de prolongarla ante las buenas perspectivas de efectividad de este procedimiento de mediación. A este respecto es posible tener en cuenta:

1) Hasta el momento se han venido desarrollando los procedimientos de mediación sobre la base de unos protocolos de actuación articulados para ordenar el procedimiento de mediación en sus diversas fases. Es muy recomendable que estos protocolos, que son el paraguas jurídico que ha ofrecido viabilidad a la mediación, deje paso a una regulación uniforme y adecuada para todas las mediaciones, fuere donde fuere el lugar en el que se practicaren.

2) Las fases en las que se ha venido estructurando el procedimiento esencialmente han sido las que a continuación se exponen, y que pudieren considerarse a efectos de una futura regulación inmediata:

a) Fase de aproximación o de contacto. Se inicia la misma por decisión del juez o del fiscal y siempre que exista inclinación favorable a la misma por parte del acusado y del abogado. En tal caso el equipo de mediación comienza a entrar en contacto con las partes, realizándose una sesión inicial en la que se suscribe un documento firmado por ambas en el que consienten de haber sido informadas de lo que es y significa la mediación. Es importante este momento porque supone la consagración del principio de voluntariedad y libertad de sometimiento a este modelo de justicia. Podrán desplegarse entrevistas individuales para valorar el interés en alcanzar una solución consensuada. 
b) Fase de encuentro o de acogida. En esta segunda fase, producto del éxito de la anterior, se llevarán normalmente a cabo entrevistas conjuntas o cualesquiera otras que permitan aun cuando se trate de actividades indirectas favorecer el acuerdo. En todo caso, la naturaleza de los hechos y las coordenadas en que los mismos se desplegaron deben jugar como condiciones de actuación de los mismos mediadores, quienes determinarán las pautas a seguir en estos casos. Ello no es óbice a que existan protocolos de actuación en atención a las diversas situaciones derivadas de una pluralidad de sujetos, o de delitos cometidos en la unidad familiar, o delitos cometidos contra el patrimonio, etcétera.

c) Fase de acuerdo o negociación. La tercera fase pretende suscribir un documento en el que se alcance el citado acuerdo, o lo que se ha denominado como el "plan de reparación". Cuando no exista éxito en la culminación del acuerdo, el mediador informará de estas circunstancias al juez o en su caso al fiscal, respetando la confidencialidad de lo que se haya venido aportando en el procedimiento de mediación.

Evidentemente es la fase en la que el éxito de la mediación se deja sentir, en cuanto si existe acuerdo los objetivos pretendidos se han conseguido, mientras que en los supuestos en que no se da acuerdo, la continuación del proceso penal se hace necesaria y los esfuerzos realizados en este procedimiento no han surtido los efectos pretendidos, beneficiosos para los sujetos en cuestión.

Es importante determinar cuál debe ser el contenido del posible acuerdo que se alcance, y ello por cuanto deberán concretarse los hechos que han sido objeto de aceptación por ambas, así como las circunstancias en que se dieron, lo que pase ineludiblemente por el reconocimiento de los hechos realizado por el infractor. La consecuencia del acuerdo deberá quedar por escrito y consistirá en la reparación, que puede ser material, consistente tanto en la entrega de una cantidad de dinero como o un hacer algo, una reparación moral consistente en la petición de perdón o simbólica, que puede incluso referirse a trabajos en beneficio de la comunidad. El acuerdo de mediación debe quedar firmado por las partes y surge la duda de si debería ratificarlo igualmente el abogado defensor, lo que vendrá determinado por el modelo procesal en el que lo ubiquemos y en el momento procesal en el que se dé. Si se trata de un supuesto de mediación remitido desde sede judicial el imputado tiene ya letrado, quien de alguna manera deberá ser partícipe de la existencia del procedimiento de mediación; lo que no tengo tan claro es que la voluntad del abogado, plasmada en su firma, debe ser elemento de efectividad del mismo.

d) Fase de ejecución. Supone la realización de las fórmulas de reparación que se hubieren pactado por las partes, y en este sentido juega aquí tanto la 
reparación material como aquella que se denomina como reparación simbólica, que debe, pese a su denominación, ser objeto de cumplimiento. A esta modalidad reparatoria se refieren igualmente la mayoría de los sistemas de derecho comparado.

Una de las cuestiones precisamente que se han venido suscitando al respecto es la del seguimiento de su cumplimiento efectivo, en cuanto a determinar quién o quiénes deberían ser los que se interesaren por el mismo. Así será el juez o el fiscal quienes asumirán ese liderazgo a la hora de requerir del equipo técnico el control del debido cumplimiento. No comparto la opinión de que deba ser el mediador cuando de adultos se trate.

Este control es decisivo en cuanto a la suerte procesal del infractor, y ello por cuanto la reparación deberá llevarse a cabo antes de que se dicte la resolución final que ponga fin al proceso penal, lo que obliga a que la ejecución del acuerdo, siquiera parcialmente, debería haberse comenzado a realizar antes de que pueda desplegarse el juicio oral. La futura legislación deberá referirse a los supuestos en que el incumplimiento de la reparación se dé, ya sea total o parcial, dado que los efectos de dicho incumplimiento deben dejarse sentir en la ejecución de la sentencia, a través de la no concesión de beneficios, o revocando los concedidos, por ejemplo, o la imposibilidad de someterse a un tratamiento rehabilitador, etc. Es obvio que el incumplimiento total debe imposibilitar de eficacia a la mediación, lo que significa que debería producirse la continuación del proceso.

En todo caso, repárese que la mediación penal en España parece estar pensada esencialmente para aquellos supuestos en que se produce la remisión a la misma por estar pendientes unas diligencias incoadas contra el infractor. Es por ello que se canalizará formalmente la mediación como un incidente en el mismo proceso, y si se alcanza el acuerdo deberá homologarse por el juez mediante auto, y si no se alcanza, deberá darse por finalizado el procedimiento de mediación por el juez mediante auto para proceder a continuar con la pieza principal.

\section{El mediador y sus características}

Finalmente, debemos hacer referencia al elemento subjetivo director de la mediación: el mediador. Hay que concretar quién puede ser mediador en un proceso penal y cuáles deberían ser las notas esenciales de su estatuto de mediador. La necesidad de garantías es nota esencial que ha preocupado tanto a los técnicos y expertos españoles que han venido experimentando en mediación como a los ordenamientos jurídicos en los que se desarrolla con eficacia este modelo de justicia restaurativa. 


\section{A) Requisitos para ser mediador}

Se entiende como la mejor de las soluciones que se institucionalice esta función a través de los servicios de mediación, interviniendo personal diverso del adscrito al juzgado (juez o secretario), inclusive excluyendo a la policía o a la fiscalía. En este sentido, habrá que tener en cuenta que la configuración de un Servicio de Mediación puede ser esencial para su buen actuar, pudiendo estar financiado por ayuntamientos, comunidades autónomas, concejalías, etc. Ahora bien, nada impide que se trate de mediadores individuales tan sólo, que podrian perfectamente asumir la función que se les atribuye en materia penal.

En cualquier caso es imprescindible la capacitación como mediador, lo que se exige de manera diversa manera dado que por un lado hay paises en los que se ha establecido la necesidad de realizar entre 250 a 300 horas para obtener el título de mediador, en otros se habla de la necesidad de además introducir la exigencia de un registro de mediadores, ${ }^{24} \mathrm{o}$ incluso se ha hablado de estar inscrito en alguna asociación o colectivo de mediadores, etc. Se trata de ofrecer esencialmente técnicas de comunicación y habilidades para el manejo de la gestión de conflictos.

\section{B) Facultades y obligaciones del mediador}

En cuanto a las facultades y obligaciones del mediador podemos tomar en consideración algunas de las propuestas del Grupo de Trabajo de Madrid para la elaboración de un texto sobre mediación penal y penitenciaria, ${ }^{25}$ entre las que se encuentran:

a) No iniciar la mediación cuando parece que no va a cumplir los fines propuestos y en general los beneficiosos para las partes.

b) Suspender, en su caso, el procedimiento de mediación cuando entienda que puede causar algún perjuicio a alguna de las partes que se hallan en conflicto.

c) Actuar en el desarrollo del procedimiento con la debida diligencia y respeto a los derechos de las partes y con flexibilidad para favorecer las bondades del modelo y los fines de la misma.

d) Contar con una copia de los autos del proceso, remitidos con anterioridad por la secretaría del juzgado.

\footnotetext{
${ }^{24}$ En este sentido parece que deberian cooperar en dicho registro el Ministerio de Justicia con las comunidades autónomas, exigiendo que se trate de registro obligatorio para poder actuar en sede de la administración de justicia. Se ha apuntado si serían posibles registros llevados a cabo por colegios profesionales, tales como Colegio de Abogados o de psicólogos. Entiendo mucho más razonable el registro general que el de colectivos y viene a determinar las mismas exigencias para todos los registrados

${ }^{25}$ Fue elaborado por Ramón Sáez, Justino Zapatero, Isabel González Cano, Julián Rios y Concepción Sáez.
} 
e) Mantener contacto con los sujetos de la mediación tantas veces como considere oportuno, manteniendo entrevistas individuales o colectivas.

f) Fijar las duraciones de cada una de las sesiones en el transcurso de la mediación.

g) Para el desempeño de estas facultades será necesario que se le otorgue un despacho, sala o espacio habilitado para llevar a cabo su función de mediador en el procedimiento correspondiente, con el fin de que los sujetos perciban esa estrecha vinculación con la Administración de Justicia.

h) Estarán por su parte obligados a: guardar la debida confidencialidad, actuar bajo los principios de imparcialidad, neutralidad y objetividad, ${ }^{26}$ iniciar el procedimiento tan sólo cuando se haya manifestado por las partes la voluntad libre de participar en él, desarrollar su actividad en el espacio otorgado y no recibir remuneración de ninguna de las partes; tiene el deber de promover el acuerdo entre ellas, poner fin al procedimiento de mediación en el plazo que se establezca en la norma correspondiente, presentando el informe con el acta de reparación, en su caso, o no, al juzgado, y siempre cumpliendo con las reglas deontológicas profesionales que correspondan.

i) Evidentemente la función de mediador es contraria a la del ejercicio simultáneo de asesoramiento jurídico como abogado de una de las partes.

\footnotetext{
${ }^{26}$ Los autores del documento consideran que para guardar estas cualidades la persona mediadora no podrá ejercer como tal cuando tenga interés personal en el asunto; vínculos de parentesco por consanguinidad hasta el cuarto grado o de afinidad hasta el segundo con alguna de las partes; amistad intima o enemistad manifiesta con alguna de las partes; cuando haya conocido de ese conflicto como consecuencia del ejercicio de su profesión de origen, o los intereses que se manejan sean contrapuestos a otros en los que esté interviniendo o haya intervenido con anterioridad. Estas causas sugeridas en el documento de trabajo pueden evitarse si las partes conocen de su existencia y a pesar de ello aceptan al mediador y lo hacen ambas de manera expresa.
} 